\title{
CORRODIBILITY OF LOW CARBON STEEL IN IMMERSION TEST USING COOLING WATER SYNTHESIS
}

\author{
Ahmad Royani ${ }^{1}$, Siska Prifiharni ${ }^{1}$, Gadang Priyotomo ${ }^{1}$, Sundjono ${ }^{1}$ \\ ${ }^{1}$ Research Center for Metallurgy and Materials, Indonesian Institute of Sciences, Indonesia \\ Emails: ahmad.royani@lipi.go.id, sisk002@lipi.go.id, Gadang-p@gmail.com, Sund002@lipi.go.id
}

\begin{abstract}
Low-carbon steel is widely used in various construction in several industries because it has good mechanical properties. Generally, the application of low-carbon steel developed does not involve corrosion resistance as a primary consideration. To find out the corrodibility of low carbon steel and the corrosiveness of the liquid, an immersion test for these steels was carried out in a cooling water synthesis. The method used in this study is the planned-interval test. The corrodibility of low-carbon steel was determined by weight loss, while the corrosiveness of the liquid was measured by a multimeter (Hach HQ40d). Morphology of corrosion products is characterized using scanning electron microscopy (SEM), energy dispersive spectrometry (EDS), and X-ray Diffraction (XRD). The result of immersion of low carbon steel in the cooling water synthesis shows that the corrosiveness of liquid tends to be constant during the immersion period with relatively similar in value of water quality parameters. Meanwhile, the corrodibility of low carbon steel decreases with the length of exposure time in the water synthesis. The less corrodibility due to the formation of layers of corrosion products. Corrosion products formed during immersion are uniform with the distribution of the dominant element in the form of iron oxide.
\end{abstract}

Keywords: Carbon Steel, Corrodibility, Interval Test, Immersion Test, Water Quality.

\section{Introduction}

In the world today, low-carbon steel is widely used in various applications in the industry because of its good mechanical properties [1-2]. Low carbon steels generally have a carbon content of less than $0.25 \%$ and are unresponsive to the heat-treatment process [3]. Low-carbon steel has exceptional toughness and toughness, high machinability, and weldability that enable engineering applications. However, lowcarbon steel applications developed generally don't involve corrosion resistance as a major consideration. The corrosion resistance of metals and alloys is a basic property associated with the ease of metals reacting with certain environments [4]. With the increased utilization of low carbon steel in manufacturing and construction companies, one of the main problems faced is corrosion and corrosion control methods when conducted in a corrosive environment.

In general, the factors that influence the corrosion rate of carbon steel depend on the characteristics of the steel itself [5], the surrounding environment, and or a combination of both [4].
Some factors related to the characteristics of metals include chemical composition, microstructure, residual stress, chemical homogeneity, and physical of the metal surface [5]. Environmental factors, especially the water environment, include hydrogen ion activity $(\mathrm{pH})$ and dissolved oxygen in solution, flow rate, total dissolved solids, and solution temperature [6-9].

In this study, an analysis of the corrosivity of liquid and corrodibility of carbon steel was to be done by an immersion test based on ASTM G-31 [10] using synthesis cooling water. The aim is to see the corrosivity of the test solution and the corrodibility of low carbon steel during the immersion test.

\section{Materials and Methods}

The low-carbon steel from the commercial market was used in this study. The chemical composition of low-carbon steel is shown in Table 1 and its microstructure in Figure 1.

The test solution used in this research is a cooling water synthesis with chemical composition is presented in Table 2.

Table 1. The chemical composition of low-carbon steel [11]

\begin{tabular}{|c|c|c|c|c|c|c|c|c|c|c|}
\hline \multicolumn{10}{|c|}{ Element (\% wt(. } \\
\hline Fe & $\mathrm{C}$ & $\mathrm{Cr}$ & $\mathrm{Ni}$ & $\mathrm{Mn}$ & $\mathrm{Mo}$ & $\mathrm{Al}$ & $\mathrm{Si}$ & $\mathrm{Cu}$ & $\mathrm{S}$ & $\mathrm{P}$ \\
\hline Bal. & 0.176 & 0.131 & 0.143 & 0.717 & 0.011 & 0.002 & 0.134 & 0.499 & 0.041 & 0.012 \\
\hline
\end{tabular}




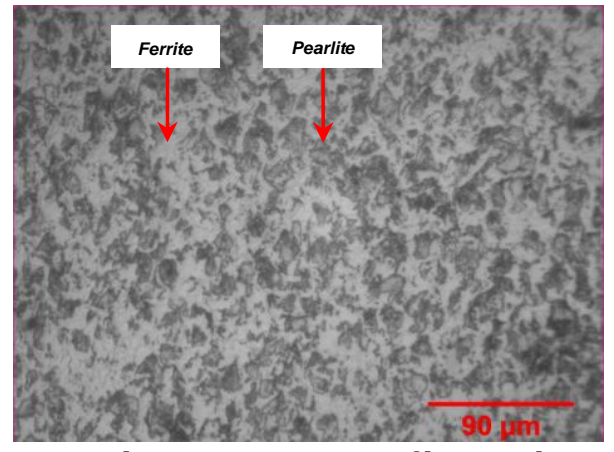

Figure 1: The microstructure of low-carbon steel specimens

Table 2. The chemical composition of cooling water

synthesis

\begin{tabular}{|l|l|l|}
\hline \multicolumn{1}{|c|}{ Parameter } & \multicolumn{1}{c|}{ Unit } & Composition \\
\hline $\mathrm{pH}$ & - & 7.95 \\
\hline Conductivity & umhos & 245 \\
\hline Dissolved solids & $\mathrm{ppm}$ & 116.9 \\
\hline Calcium Hardness & $\mathrm{ppm}, \mathrm{CaCO}_{3}$ & 1.3 \\
\hline Total Hardness & $\mathrm{ppm}, \mathrm{CaCO}_{3}$ & 26.17 \\
\hline Total Alkalinity & $\mathrm{ppm}, \mathrm{CaCO}_{3}$ & 28 \\
\hline Temperature & ${ }^{\circ} \mathrm{C}$ & 37 \\
\hline Salinity & $\mathrm{ppt}$ & 0.12 \\
\hline
\end{tabular}

\section{1. Preparation of Specimen}

The carbon steel plate was cut to size $70 \mathrm{~mm} \times 20$ $\mathrm{mm} \times 2 \mathrm{~mm}$ and then gave a hole and code in the position of the top end. Before the immersion test, the surface of the specimen is cleaned according to the ASTM G-1 standards [12]. After cleaning, carbon steel specimens were weighed using analytical scales and then stored in a desiccator.

\section{2. Immersion Test}

Carbon steel specimens were inserted into an immersion test equipment (Figure 2 ) by hanging the specimen on the holder with a string. The test solution is put in a beaker glass until that the specimen position is fully submerged and then put into a water batch.

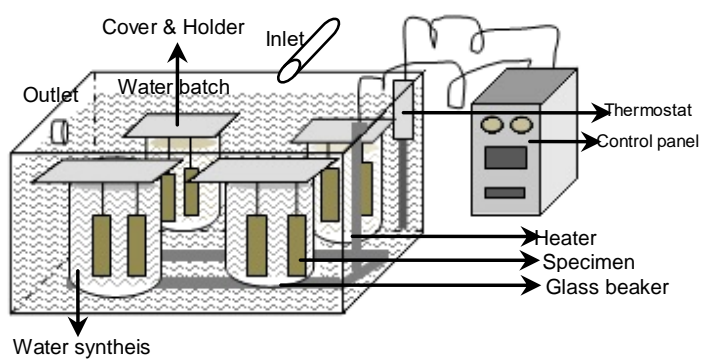

Figure 2: Schematic equipment for immersion test of corrosion
The immersion device is turned on by turning the power switch to the ON position. Set the water level and temperature, the quality parameters of the test solution are measured with a sensor probe (MultiMeter HQ40d). After the desired temperature has been reached, the specimen is put into the test solution and then closed and left for a certain exposure of time. The methods used in this immersion test uses the planned-interval test method. The schematic of the interval test is illustrated in Figure 3 and explained in Table 3.

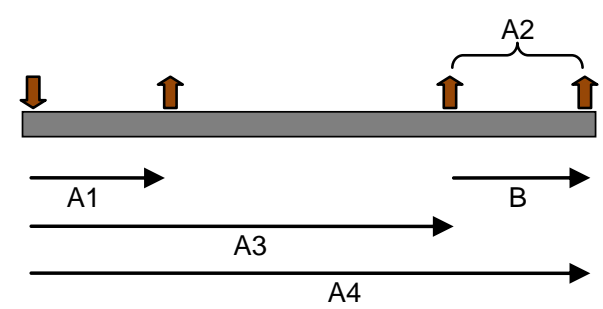

Figure 3: Schematic design of the planned-interval test

Table 3. Duration time of the interval for the immersion test of carbon steel

\begin{tabular}{|c|c|c|c|c|}
\hline \multirow{2}{*}{ No } & \multirow{2}{*}{ Code } & \multicolumn{2}{|c|}{ Time (in monthly) } & \multirow{2}{*}{$\begin{array}{c}\text { Duration } \\
\text { (days) }\end{array}$} \\
\cline { 3 - 4 } & & In & Out & 28 \\
\hline 1 & A1 & 0 & 1 & 84 \\
\hline 2 & A3 & 0 & 3 & 112 \\
\hline 3 & A4 & 0 & 4 & 28 \\
\hline 4 & B & 3 & 4 & ${ }^{*} \mathrm{~A} 2=\mathrm{A} 4-\mathrm{A} 3$ \\
\hline
\end{tabular}

\section{3. Weight Loss Analysis}

After the immersion test, the specimens are cleaned according to the procedure in ASTM G-1 standards [12]. Weighing the specimen before and after the immersion test to determine weight loss. The method for determining the corrosion rate based on weight loss follows the following equation (1):

$$
\mathrm{CR}=\mathrm{k}\left(\frac{\mathrm{W}}{\rho \mathrm{At}}\right)
$$

where:

k: coefficient constants; W: weight loss (grams); $\rho$ : density of low carbon steel $\left(\mathrm{g} / \mathrm{cm}^{3}\right)$; A: area of exposure $\left(\mathrm{cm}^{2}\right)$ and $\mathrm{t}$ : exposure time (hours).

\section{4. Measurement of Water Quality}

The quality parameters of the test solution are measured by using a portable multimeter (Hach HQ40d). The parameters measured include dissolved oxygen content (DO), salinity, conductivity, temperature, TDS (total dissolved solids), and pH. Water quality measurements are carried out at the 
beginning of immersion and each test specimen collection.

\section{5. Characteristics of Corrosion Product}

Morphology of corrosion products attached to the surface of carbon steel specimens were observed using SEM (scanning electron microscopy) JEOL JSM6390A which was equipped with EDS (energy dispersive spectrometry). $10 \mathrm{~mm}$ working distance and $20 \mathrm{kV}$ acceleration voltage are used. The corrosion product formed was analyzed by using an X-ray diffractometer (Shimadzu XRD 7000).

\section{Results and Discussion}

\section{1. Characteristics of specimen and water}

Based on the results from the chemical composition, as shown in Table 1, this steel specimen used in this work included carbon steel AISI 1018. These steel specimens contained ferrite grains (white area) and nodules of pearlite structures (dark area). From Figure 1, it can be seen that the dominant phase is the ferrite phase $(65 \%)$, and the pearlite phase is around 35\% with an oval shape. Meanwhile, the tendency of water was determined by an LSI index [13], and it's the results at $37{ }^{\circ} \mathrm{C}$ is negative $(-2.16)$. Therefore, the quality of the fluid tests in this study was categorized to form corrosive.

\section{2. Corrosion Rate}

The corrosion rate of low-carbon steel from the immersion results is determined based on the weight-loss method. The results of the corrosion rate of low-carbon steel based on the time of exposure are presented in Figure 4.

\section{Corr. Rate of Low Carbon Steel}

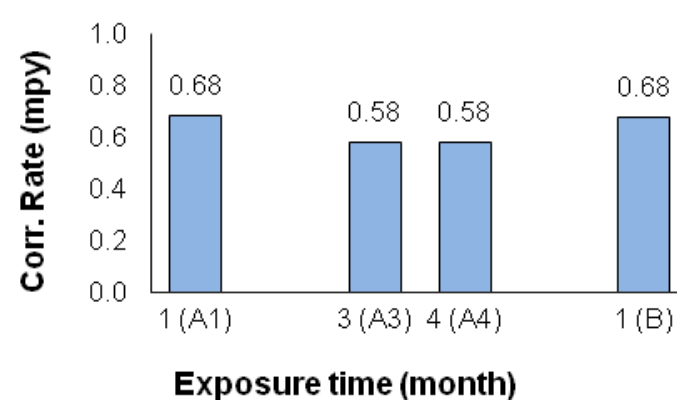

Figure 4: Corrosion rate versus exposure time

Based on the graph in Figure 4, it can be seen that the corrosion rate in the first month (A1) and the last month (B) tends to be the same. These results indicate that the nature of the corrosivity of the test solution does not change. The results of reducing the corrosion rate in the fourth month (A4) and the third month (A3) are lower than the results of the corrosion rate in the last month (B), indicating that the metal's corrodibility is declining. The reduced corrodibility of metals due to reduced contact between the metal surface and the test solution along with the formation of corrosion products on the metal surface. The same thing can also be seen in the test results in the third month (A3) and fourth month (A4) which are smaller when compared to the first month (A1). The comparisons as criteria for the changes are tabulated in Table 4. Also given in Table 4 are the criteria for all possible combinations of changes in corrosiveness of the medium and corrodibility of the metal.

Table 4. Occurrences during the corrosion test [3]

\begin{tabular}{|c|c|c|c|}
\hline No & $\begin{array}{c}\text { Liquid } \\
\text { corrosiveness }\end{array}$ & $\begin{array}{c}\text { Metal } \\
\text { corrodibility }\end{array}$ & Criteria \\
\hline 1 & Unchanged & Unchanged & $\mathrm{A}_{1}=\mathrm{A}_{2}=\mathrm{B}$ \\
\hline 2 & Unchanged & Decreased & $\mathrm{A}_{2}<\mathrm{B}=\mathrm{A}_{1}$ \\
\hline 3 & Unchanged & Increased & $\mathrm{A}_{1}=\mathrm{B}<\mathrm{A}_{2}$ \\
\hline 4 & Decreased & Unchanged & $\mathrm{A}_{2}=\mathrm{B}<\mathrm{A}_{1}$ \\
\hline 5 & Decreased & Decreased & $\mathrm{A}_{2}<\mathrm{B}<\mathrm{A}_{1}$ \\
\hline 6 & Decreased & Increased & $\mathrm{A}_{1}>\mathrm{B}<\mathrm{A}_{2}$ \\
\hline 7 & Increased & Unchanged & $\mathrm{A}_{1}<\mathrm{A}_{2}=\mathrm{B}$ \\
\hline 8 & Increased & Decreased & $\mathrm{A}_{1}<\mathrm{B}>\mathrm{A}_{2}$ \\
\hline 9 & Increased & Increased & $\mathrm{A}_{1}<\mathrm{B}<\mathrm{A}_{2}$ \\
\hline
\end{tabular}

The presence of a corrosion product layer obstructs metal surface contact so that the corrosion rate decreases with the length of time of exposure [14]. The corrodibility of the metal in a test may decrease as a function of time owing to the formation of a protective scale or the removal of the less resistant surface layer of metal [3]. The result of the corrosion rate included in the excellent category for open recirculation systems. The classification for the corrosion rate of carbon steel in open-water cooling systems is presented in Table 5 .

Table 5. The category of corrosion rate for carbon steel in the open recirculated system [15]

\begin{tabular}{|c|c|}
\hline Corrosion rate (mpy) & Category \\
\hline $1 \leq$ & Excellent \\
\hline $3-1$ & Very good \\
\hline $5-3$ & Good \\
\hline $8-5$ & Moderate \\
\hline $10-8$ & Poor \\
\hline $10<$ & Very poor \\
\hline
\end{tabular}

\section{3. Analysis of Water Quality}

The corrosion rate of steel depends on several parameters such as the chemical composition of the steel [16], surface roughness, and environment [6]. 
The parameter of the water environment includes conductivity, total dissolved solids, salinity [17], dissolved oxygen (D0) [18], temperature, and $\mathrm{pH}[19]$.

The measurement results of the conductivity and TDS in the test solutions at various immersion times have relatively the same values as shown in Figure 5 and Figure 6. These results indicate that the liquid corrosiveness of solution tests did not change as evidenced by the results of the same corrosion rate in the first month (A1) and the last one-month (B). Theoretically, the corrosion rate of steel in water environments with high conductivity tends to be greater than in water environments with low conductivity [6].

\section{ConductivityVs Exposure Time}

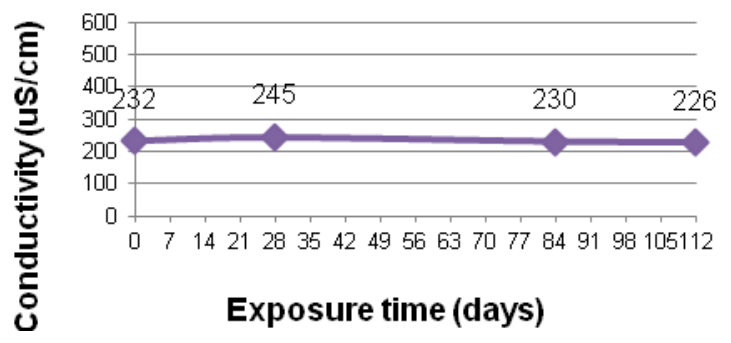

Figure 5: The results of the conductivity versus exposure time

Because the conductivity and TDS are relatively constant during the immersion test, so those parameters do not have a significant effect on the corrosion rate of low carbon steel. However, in theory, the total dissolved of solids and high conductivity could increase corrosion rates [6]. This relates to the moving of the ion exchanges at the cathode and the anode more happened so that the rate of mass transfer of ions is faster [20].

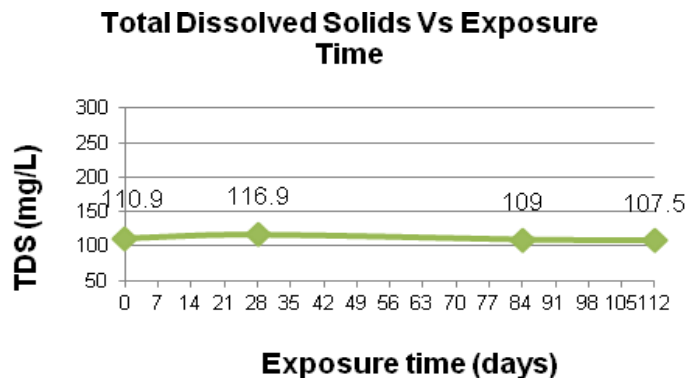

Figure 6: The results of the total dissolved solids versus exposure time

The results of measuring the $\mathrm{pH}$ of the test solution versus time are presented in Figure 7 . The results of measuring the $\mathrm{pH}$ of the test solution show the $\mathrm{pH}$ value of the solution that did not experience a significant change, where the measured $\mathrm{pH}$ is between $\mathrm{pH} 7.7$ and 8.11. Based on the results of this $\mathrm{pH}$ measurement, the test solution is included in a neutral environment that has little influence on the rate of corrosion. However, a decrease in $\mathrm{pH}$ can make the environment more acidic and consequently the environment becomes more corrosive [13]. The effect of $\mathrm{pH}$ on the solubility of corrosion products formed during the corrosion process is often the key to understanding metal concentrations in the aquatic environment.

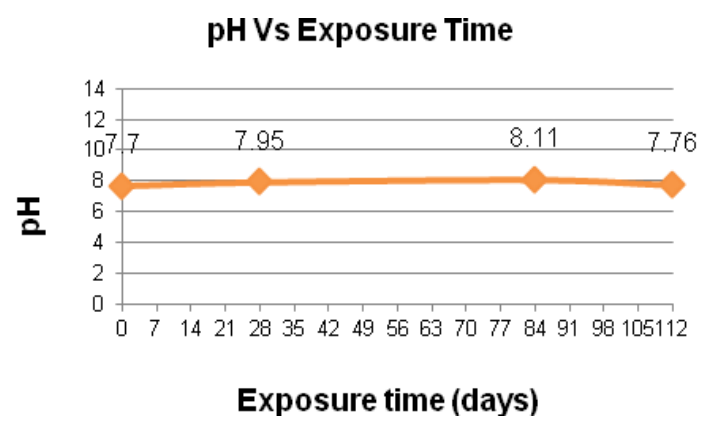

Figure 7: The results of $p H$ in the aqueous test versus exposure time

Liquid corrosiveness of the solution is not only a function of water resistivity and acidity but is also influenced by complementary, additional factors such as salinity, dissolved gas content, and temperature [14].

Salinity is defined as the amount of chloride content in water. Therefore, salinity is predicted by determining the concentration of $\mathrm{Cl}^{-}$ions in water. The empirical relationship between salinity and content of $\mathrm{Cl}^{-}$ions are formulated in equation (2) [13]:

\section{$1.80655 \times\left[\mathrm{Cl}^{-}\right]$}

The salinity measurement results of the test solution during the immersion time are presented in Figure 8. The resulting salinity is relatively the same and the value is very small namely between $0.11 \mathrm{ppt}$ and $0.12 \mathrm{ppt}$. These results indicate that the test solution used in the simulation process is included in the category of freshwater because the chloride ion content is below 1000 ppm [13].

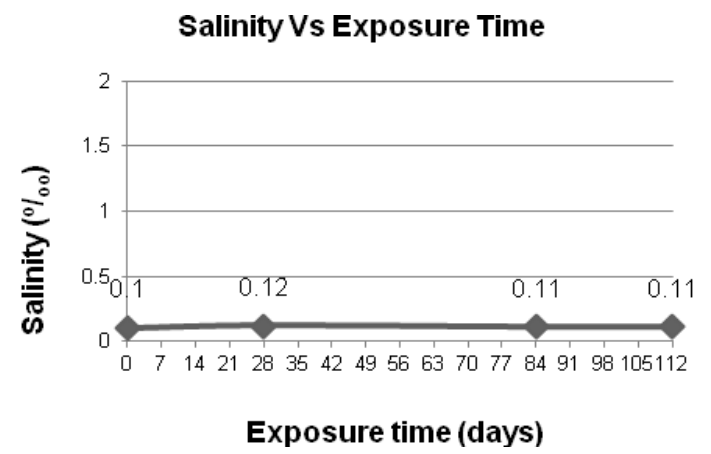

Figure 8: The results of the salinity versus exposure time

The corrosivity of natural water (natural water) increases proportionally if the value of salinity increases. If salinity exceeds $3 \%$, water corrosivity will decrease [17]. This phenomenon is caused by 
the fact that the corrosion rate tends to increase when the water conductivity increases. The higher the salinity, the lower the oxygen solubility [6]. Thus, salinity above $3 \%$, the rate of corrosion in the water decreases. Likewise, if salinity is very small, then the effect is very small on the rate of corrosion.

Another quality parameter that affects the rate of corrosion in the water environment is the dissolved gas content. Dissolved gas that affects the corrosivity of the solution is oxygen and carbon dioxide. The solubility of oxygen and carbon dioxide decreases with increasing temperature and salinity [21]. Carbon dioxide gas can affect the $\mathrm{pH}$ of the solution, the presence of $\mathrm{CO}_{2}$ gas makes the solution more acidic [21]. The oxygen acts as a cathodic depolarization and increases the occurrence of the corrosion process [18].

The results of the measurement of dissolved oxygen content versus immersion time using a portable Multimeter (Hach HQ40d) are shown in Figure 9.

\section{Dissolved Oxygen Vs Exposure Time}

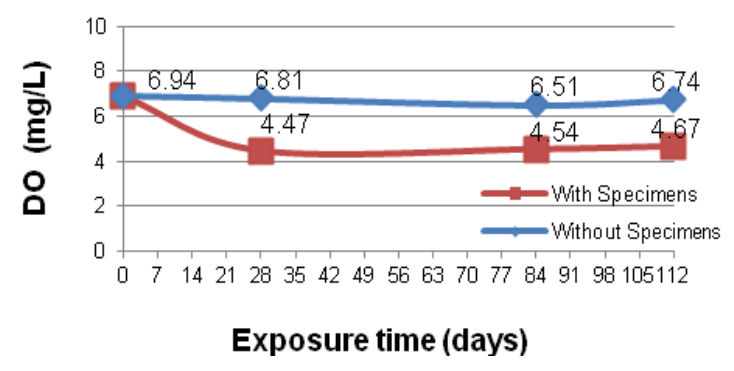

Figure 9: The results of dissolved oxygen versus exposure time

Based on the data in Figure 9, it is clear that the effect of oxygen is seen on the corrosion rate. DO values decreased in the solution with the test specimen while the blank solution (without specimen) was relatively stable from the beginning to the end of the immersion test. In the beginning, the corrosion initiation process began to occur in the anodic region so that oxygen consumption in the cathodic region increased. As a result of corrosion events, oxygen dissolved in water decreases. The mechanism of chemical reactions occurring corrosion in the neutral solution environment according to the following reaction equation:

At the anode area, iron ( $\mathrm{Fe}$ ) dissolves into iron $\left(\mathrm{Fe}^{2+}\right)$ ions:

$$
\mathrm{Fe} \rightarrow \mathrm{Fe}^{2+}+2^{\mathrm{e}-}
$$

whereas at the cathode, a dissolved oxygen reduction reaction occurs:

$$
\mathrm{H}_{2} \mathrm{O}+1 / 2 \mathrm{O}_{2}+2^{\mathrm{e}-} \rightarrow 2 \mathrm{OH}^{-}
$$

The above reactions occur simultaneously and in fact, a variety of further reactions occur in the solution. In the event of corrosion, iron ions $\left(\mathrm{Fe}^{2+}\right)$ formed at the anode will oxidize to form iron oxide in the form of a very thin rust layer on the metal surface and inhibit further iron dissolution:

$$
\mathrm{Fe}^{2+}+2^{\mathrm{e}-}+1 / 2 \mathrm{O}_{2} \rightarrow \mathrm{FeO}
$$

Likewise, at the cathode, oxygen must reach the metal surface for the reaction (4) to occur. Hydroxyl $\left(\mathrm{OH}^{-}\right)$ions that are formed can also be absorbed on the surface to form a layer that blocks the absorption of oxygen. In this situation, the cathode polarization occurs and the corrosion process runs slowly. In a very rapid corrosion reaction, the barrier layer (protective) does not get formed, Fe ions react with hydroxyl ions:

$$
2 \mathrm{Fe}^{2+}+4 \mathrm{OH}^{-}+1 / 2 \mathrm{O}_{2}+\mathrm{H}_{2} \mathrm{O} \rightarrow 2 \mathrm{Fe}(\mathrm{OH})_{2}
$$

From the experimental results (Figure 9) and by with the reactions above, it can be said that DO is the most dominant parameter in the process of steel corrosion. It was even reported that internal corrosion of water pipes can be effectively prevented by reducing DO concentrations [19].

One of the parameters of the quality of the test solution that affects the corrosivity of the solution is the temperature of the solution. In general, the temperature can increase the corrosion rate exponentially with every $10{ }^{\circ} \mathrm{C}$ increase [13]. Thus it can be said that hot water is more corrosive than cold water. In a closed condition system, the level of corrosion rates is tripled or quadrupled when the temperature of the solution rises. However, the corrosion rate of steel metals reaches a maximum price of $80^{\circ} \mathrm{C}$ in an open condition system [22]. This is because at temperatures above $80{ }^{\circ} \mathrm{C}$ oxygen gas evaporation occurs into the atmosphere. The results of measuring the temperature of the test solution during the immersion process are presented in Figure 10.

\section{Temperature Vs Exposure Time}

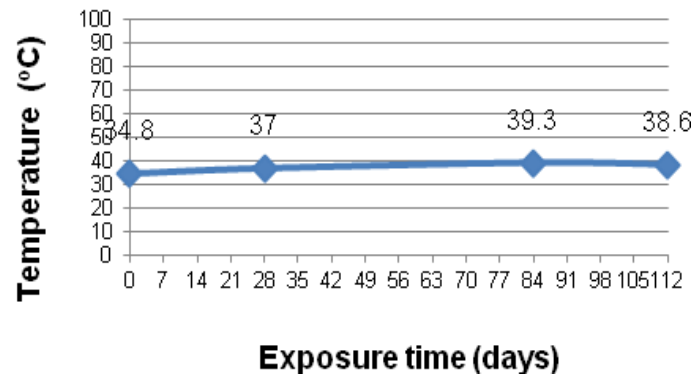

Figure 10: The results of the temperature versus exposure time

In this study, the temperature parameters of the solution were kept constant at $37{ }^{\circ} \mathrm{C}$ and did not experience a significant change. The results of the measurement temperature of the test solution ranged from $34.8{ }^{\circ} \mathrm{C}$ to $39.3{ }^{\circ} \mathrm{C}$. The temperature parameters of the solution in this immersion test do not affect the rate of corrosion due to insignificant 
changes (below $10{ }^{\circ} \mathrm{C}$ ) and under open-system conditions.

The quality of the test solution parameters above not only affects the corrosivity of the solution and the corrosion rate. However, these parameters also affect the characteristics of the corrosion product.

\section{4. Corrosion Product}

The morphology of the corrosion products formed on the surface of low-carbon steel specimens is shown in Figure 11 with the EDS results in Figure 12. Carbon steel is very easy to react with dissolved oxygen in the water. The reaction becomes oxide hydrate, which is a corrosion product. When viewed from the morphology and forms of corrosion identified the forms of corrosion that are formed evenly as shown in Figure 11.

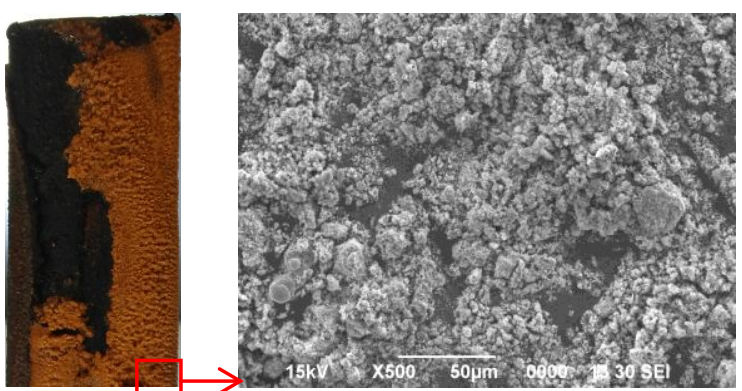

Figure 11: The visual and a photograph of corrosion products

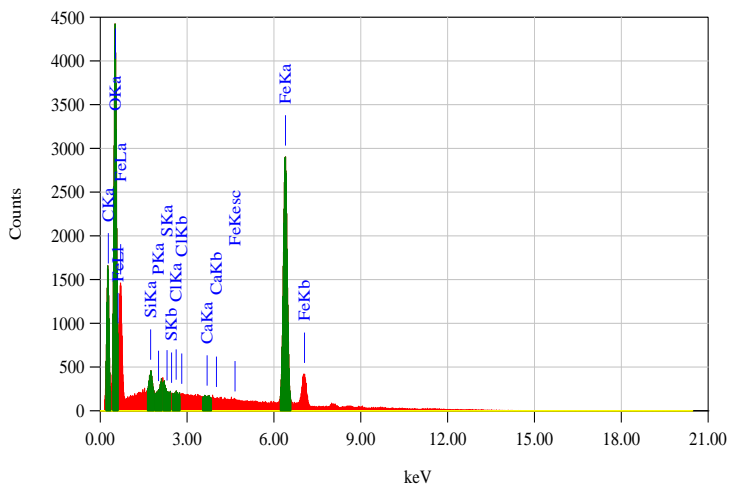

Figure 12: The EDS (scan area) of the corrosion product (magnification:500x)

The results of SEM and EDS indicate qualitatively the dominant elements in corrosion products are iron, carbon, and oxygen. The content of the chemical composition of the constituent elements of corrosion products is $68.86 \% \mathrm{Fe} ; 16.32 \% \mathrm{O}_{2}$; $14.05 \% \mathrm{C} ; 0.62 \% \mathrm{Si} ; 0.11 \% \mathrm{Cl}$ and $0.04 \% \mathrm{Ca}$. The distribution of dominant elements, especially iron and oxygen, is present on the entire surface of carbon steel as shown in the photo mapping results in Figure 13.
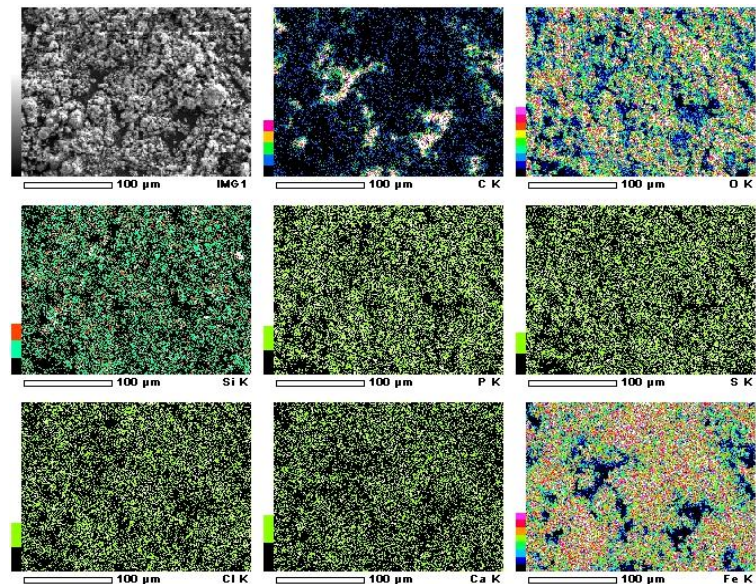

Figure 13: The results of the mapping distribution of elements of corrosion products on carbon steel

Based on the results of the mapping in Figure 13 shows the formation of iron oxides. This also causes weight gain that occurs in corroded metals.

The results of the morphology and therefore the content of the elements that haven't been ready to predict the shape of corrosion product compounds. Therefore, to see the compound shape of the corrosion product, an analysis using XRD (x-ray diffraction) was performed. The results of the XRD analysis on corrosion products are shown in Figure 14.

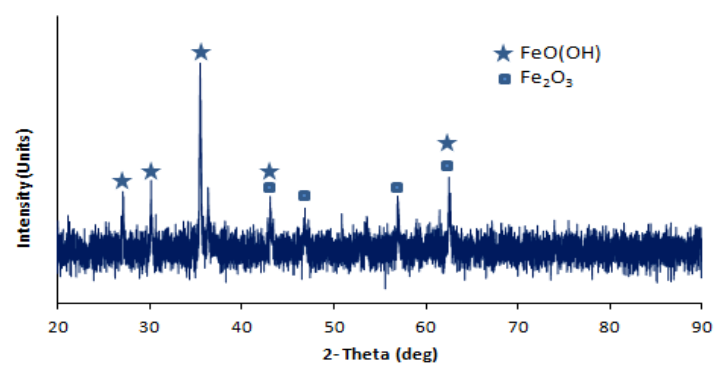

Figure 14: The result of X-ray diffraction patterns from corrosion products

Data obtained from the XRD ends up in the shape of a spectrum which states the intensity as a function of 2-Theta. The results of XRD from the experiment were matched with an identical diffractogram of information. After matching, the oxides which are formed on the surface of steel are within the type of $\mathrm{FeOOH}$ and $\mathrm{Fe}_{2} \mathrm{O}_{3}$ oxides.

\section{Conclusions}

In the experimental immersion of low carbon steel in a cooling water synthesis solution, the corrosivity of the test solution tends to be constant during the immersion with relatively similar test quality parameters. While the low-carbon steel corrodibility decreases with the length of immersion time in the test solution. The decrease in corrodibility is identical to the lower corrosion rate at a longer soaking time due to the formation of a corrosion 
product layer. Corrosion products formed during immersion are evenly distributed with the distribution of the dominant element in the form of iron oxide in the form of $\mathrm{FeO}(\mathrm{OH})$ and $\mathrm{Fe}_{2} \mathrm{O}_{3}$.

\section{Acknowledgments}

The author would like to thank the Research Center for Metallurgy and Material - LIPI for the support of corrosion laboratory facilities.

\section{References}

[1] Borzouyi Kutenayi, S., Kiahosseini, S. R., Talebpour, M. H., "The Effect of Caspian Sea Water on Corrosion Resistance and Compressive Strength of Reinforced Concrete Containing Different $\mathrm{SiO}_{2}$ Pozzolan", International Journal of Engineering, Transactions A: Basics, Vol. 30, No. 10, (2017), 1464-1470.

[2] Gandy, D., "Carbon Steel Handbook: Final Report", California, Electric Power Research Institute, (2007).

[3] Nazma, S., Ferdaus, H. and Mehedi, I., "Analysis of Mechanical Properties of mild steel Applying Various Heat treatment", in Int. Conf. on Mech., Industrial and Energy Engineering, (2014).

[4] Fontana, G. M., "Corrosion Engineering”, 3th ed, Singapore, McGraw-Hill International Editions, (1987).

[5] Munasir, N., Triwikantoro, Zainuri, M., Bäßler, R. and Darminto, "Corrosion Polarization Behavior of $\mathrm{Al}-\mathrm{SiO}_{2}$ Composites in $\mathrm{NaCl} 1 \mathrm{M}$ and Related Microstructural Analysis", International Journal of Engineering, Transactions A: Basics, Vol. 32, No. 7, (2019), 982-990.

[6] Bennett, P. B., "Control of environmental variables in water: Resirculating system", Metal Handbook, 9th ed, New York, Calgon Corporation, (1992), 487-497.

[7] Noori, M., Momeni, M. and Moayed, M. H., "Inhibitive Assesment of Stearamide as a Corrosion Inhibitor for Mild Steel in $\mathrm{HCl}$ Solution", International Journal of Engineering, Transactions C: Aspects, Vol. 25, No. 2, (2012), 119-125.

[8] Paul Guyer, J., "An Introduction to cooling tower water treatment", California, Continuing Education and Development, Inc, (2014).

[9] Khavasfar, A., "An Investigation on The Performance of An Imidazoline Based Commercial Corrosion Inhibitor on $\mathrm{CO}_{2}$ Corrosion Of Mild Steel", International Journal of Engineering, Transactions A: Basics, Vol. 20, No. 1, (2007), 35-44.
[10] ASTM G31, "Standard Practice for Laboratory Immersion Corrosion Testing of Metals", The American Society for Testing and Materials, (2004).

[11] Royani, A., Prifiharni, P., Priyotomo, G., Triwardono, J. and Sundjono, "Corrosion of carbon steel in synthetic freshwater for water distribution systems", in Conf. Series: Earth and Env. Sci. 399, 012089, (2019).

[12] ASTM G1, "Standard Practice for Preparing, Cleaning, and Evaluating Corrosion Test Specimens", The American Society for Testing and Materials, (1999).

[13] Roberge, P. R., "Corrosion engineering: principles and practice, New York, McGraw-Hill, (2008).

[14] Royani, A., Prifiharni, S., Priyotomo, G., Triwardono, J. and Sundjono, "Corrosion Performance of Carbon Steel in Pipe Simulation Test for Cooling Water Systems", Metalurgi, Vol. 34. No. 2, (2019), 49-60.

[15] Bennett, P. B., Standards for Corrosion Rates, AWT Analyst, Spring, (2000).

[16] Royani, A., Nuraini, L., Prifiharni, S., Priyotomo, G. and Sundjono, "Corrosion rate of various carbon steels in raw water for water cooling system at ammonia plant", Int. J. of Eng. Trends and Tech. (IJETT), Vol. 59, No. 1, (2018), 51-58.

[17] Zakowski, K., Narozny, M., Szocinski, M. and Darowicki, K., "Influence of water salinity on corrosion risk-the case of the southern Baltic Sea coast", Environ Monit Assess, Vol. 186, (2014), 4871-4879.

[18] Jung, H., Kim, U., Gyutae, S., Hyundong, L. and Chunsik, L., "Efect of dissolved oxygen (DO) on internal corrosion of water pipes", Environ. Eng. Res., Vol. 14, No. 3, (2009), 195-199.

[19] Qingwei, N., Zili, L., Gan, C. and Bingying, W., "Effect of flow rate on the corrosion behavior of N80 steel in simulated oil field environment containing $\mathrm{CO} 2$ and HAc", Int. J. Electrochem. Sci., Vol. 12, (2017), 10279-10290.

[20] Li, H., Hsieh, M. K., Chien, S. H., Monnell, J. D., Dzombak, D. A. and Vidic, R. D., "Control of mineral scale deposition in cooling systems using secondary-treated municipal waste water", Water Research, Vol. 45, (2011), 748760.

[21] Ziqiang, L., Jiuju, C., Wenqiang, S. and Wang, L., "Analysis and optimization of open circulating cooling water system", Water, Vol.10, (2018).

[22] Uhliq H. H. and Revie R. W., "Corrosion and Corrosion Control: An Introduction to Corrosion Science and Engineering", 4th ed, Canada, John Wiley \& Sons, (2008). 